\title{
Lusioersily
}

\section{Implementation of Interactive and Adjustable Cloudbased e-Learning Tools for 21st Century Engineering Education: Challenges and Prospects}

\begin{abstract}
Uhomoibhi, J., Cherner, Y., Mullett, G., Kuklja, M., Mkude, C., Fweja, L., \& Wang, H. (2019). Implementation of Interactive and Adjustable Cloudbased e-Learning Tools for 21st Century Engineering Education: Challenges and Prospects. Paper presented at III IEEE World Engineering Education Conference EDUNINE2019, Lima, Peru.
\end{abstract}

Link to publication record in Ulster University Research Portal

Publication Status:

Published (in print/issue): 17/03/2019

\section{Document Version}

Author Accepted version

\section{General rights}

Copyright for the publications made accessible via Ulster University's Research Portal is retained by the author(s) and / or other copyright owners and it is a condition of accessing these publications that users recognise and abide by the legal requirements associated with these rights.

\section{Take down policy}

The Research Portal is Ulster University's institutional repository that provides access to Ulster's research outputs. Every effort has been made to ensure that content in the Research Portal does not infringe any person's rights, or applicable UK laws. If you discover content in the Research Portal that you believe breaches copyright or violates any law, please contact pure-support@ulster.ac.uk. 


\section{Implementation of Interactive and Adjustable Cloud- based e-Learning Tools for 21 st Century Engineering Education: Challenges and Prospects}

\author{
Yakov E. Cherner \\ ATeL-Advanced Tools for \\ e-Learning \\ Swampscott, Mass, USA \\ ycherner@atelearning.com \\ Catherine Mkude \\ Open University of Tanzania \\ Dar es Salaam, Tanzania \\ catherine.mkude@out.ac.tz
}

\author{
James Uhomoibhi \\ Ulster University \\ Belfast, UK \\ j.uhomoibhi@ulster.ac.uk
}

\author{
Garry Mullett \\ Sprinfield Technical \\ Community College \\ Springfild, MA, USA \\ gmullett@stcc.edu
}

\author{
Leonard Fweja \\ MOOCAfrica \& Open University of Tanzania \\ Dar es Salaam, Tanzania \\ leonard.fweja@out.ac.tz
}

\author{
Maija M. Kuklja \\ University of Maryland \\ College Park, MD, USA \\ mkukla@umd.edu
}

Hui Wang

Ulster University

Belfast, UK

h.wang@ulster.ac.uk

\begin{abstract}
Online courses in engineering, technology and natural sciences in most parts of the world suffer from the lack of practical hands-on experimentation as an integral part of the curriculum being provided. The use of virtual labs and equipment facilitates active online learning. This meets habits of today's students who are always online and serves to fully engage them in STEM learning. This paper discusses the challenges and prospects of implementing simulation-based adjustable online learning activities, v-labs and comprehensive e-learning environments for teaching subjects, such as energy efficiency, renewable energy sources, thermodynamics, materials science, and some others to diverse cohorts of students from different parts of the world. The virtual labs were integrated with various online courses, including massive open online courses (MOOC) platforms. The use of these tools results in deeper understanding and transferable knowledge and skills for the learners.
\end{abstract}

Keywords-online learning, virtual laboratories, energy efficiency, IoT, MOOC, virtual reality, gamification

\section{INTRODUCTION}

Today, online courses in natural sciences, engineering, and technology offered by many colleges and universities around the world lack hands-on practice that is an essential part of any conventional science or engineering curricula. In addition, requirements for engineering education have changed dramatically following an ongoing integration of information technology and networking in production technology and everyday life. Laboratory experiences should be available for a greater number of students in engineering education, especially, when the number of students is ever more on the increase.

This paper presents an innovative e-learning environment built primarily around a virtual energy efficient house (v-EEH) [1], virtual X-Ray Laboratory (v-XRLab) [2, 3] and online educational modules focused on vehicle engines and power plants [3]. Interactive virtual laboratories (v-Labs) can partially substitute actual equipment and facilitate authentic online experimentation. V-Labs can also supplement and extend physical labs, prepare students to hands-on practice and address some educational drawbacks and limitations of real equipment.

Interactive virtual equipment has the potential to address the problem of limited availability of actual modern research and production equipment for the vast majority of students due to their extremely high cost and uniqueness. Additionally, advanced research equipment is typically fully computerized with most tasks (except sample preparation and installation), which are executed routinely without user involvement. Procedures such as equipment calibration, data collection, data handling and interpretation that directly impact experimental results are performed automatically. While this provides enormous benefits for researchers, it also creates a number of substantial educational shortcomings.

Potentially, V-Labs can overcome the above-mentioned problems and to transform "e-learning by reading and watching" into a more effective "e-learning by doing". The system design adapts and integrates cognitive information processing, systems analysis, and adult learning theories, and meets learning habits of today's students. Students acquire new knowledge while mastering complex operational and maintenance skills. According to contextual learning theory, learning skills and acquiring knowledge "in context" is the most efficient learning strategy [4].

Though there is an abundance of available interactive online resources, they are generally not flexible and customizable and cannot be tailored to a specific course, learning objectives, student levels and backgrounds, etc.

The proposed e-learning environments are based on constructivism and experiential learning theory [4-6]. They are made up of a set of interactive online modules and v-Labs. They include online lessons, assessments, a glossary, and supporting 
materials. Each of these v-labs has a flexible multi-layered and open-ended architecture. All learning and teaching resources are based on the uniform constructivist pedagogical approach and conceptually organized in such a way that they compliment each other and enable students to tackle a leaning subject from several directions.

\section{RESOURCES}

Highly interactive simulations form pillars of the described cloud-based e-learning environment. Each simulation incorporates a solid science/math model that accurately reproduces a design and operation of actual devices/systems, natural processes, or learning situations. Simulations facilitate online experimentation and exploration and enable learners to explore links between fundamental principles and their practical applications.

Simulations are key components of Guided Virtual Assignments (GVAs) (or Virtual Experiments - VEs), each of which is an integrated self-directed learning (or training) unit designed to achieve particular learning or training objectives. In addition to a main simulation, a GVA (Fig.1) includes a step-bystep performance instruction, optional worksheet and task related documentation, links to databases, as well as an embedded assessment and associated multimedia learning resources for just-in-time learning. A GVA may also include synchronized auxiliary simulations that extend the functionality of the main simulation (e.g. visualize hidden processes or explore phenomena from different perspectives). Simulations can exchange data and be synchronized with each other. The student is expected to follow a thorough set of step-by-step instructions to accomplish an educational assignment.

The GVA framework can incorporate third-party simulations and other multimedia resources. GVA's could also be easily integrated with various offline and online courses including those delivered via MOOC (massive open online course) platforms and organizational LMS. The complimentary authoring tool enables an instructor to tailor an online activity to specific learning objectives, students' levels and backgrounds.

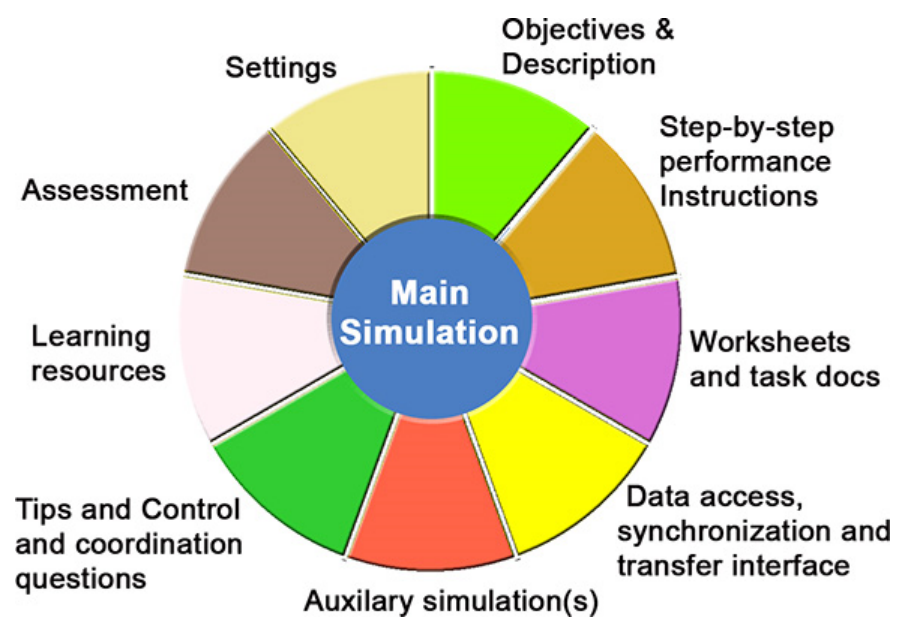

Fig. 1. GVA content diagram
Simulation-based online modules can run in four different modes:

- In Tutorial mode, which introduces students to the major processes and equipment design and operation.

- In Practice mode where students, following scenario and step-by-step instruction, perform interactive virtual assignments that perfectly mirror common workplace tasks.

- In Assessment mode, where performance-based and sequential tests provide faculty with reliable data on student skills and understanding and help students self-evaluate their knowledge and progress.

- Interactive Manual mode, which involves sequentially visualizing procedures and steps demonstrating how to perform them to accomplish a required task.

Below, we will illustrate the implementation of the concept of Interactive and Adjustable Cloud-based e-Learning Tools and discuss its merits and shortcomings.

\section{VIRTUAL ENERGY EFFICIENT HOUSE}

Interactive Energy Efficient House (Fig.2) is an integrated simulation-based reconfigurable educational environment designed to enable a wide range of users, including secondary and higher education students and general public, to explore energy consumption by major home systems and appliances, get familiar with the domestic use of renewable energy sources, and adapt an energy-responsible behavior.

It is aimed at helping students study underlying fundamental principles and related STEM subjects, as well as enhancing the understanding of technical concepts and the economic aspects of using energy efficient devices and techniques.

The virtual house, which is a core component of the elearning environment, represents a typical US residential house and incorporates all major domestic systems, home appliances, energy sources, etc. The environment also includes Authoring Tools, Learning Management System (LMS), supplemental resources, and cyberinfrastructure.

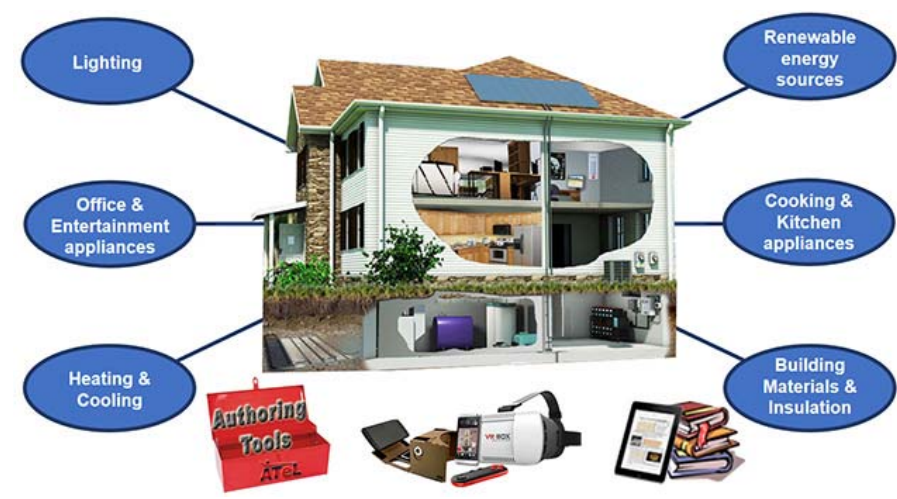

Fig. 2. Diagram of systems and tools associated with v-EEH.

Users can customize the virtual house by selecting various home appliances, lights, solar panels, heaters or air conditioners, etc. Parameters of subsystems and objects can be varied as well (Fig.4). 


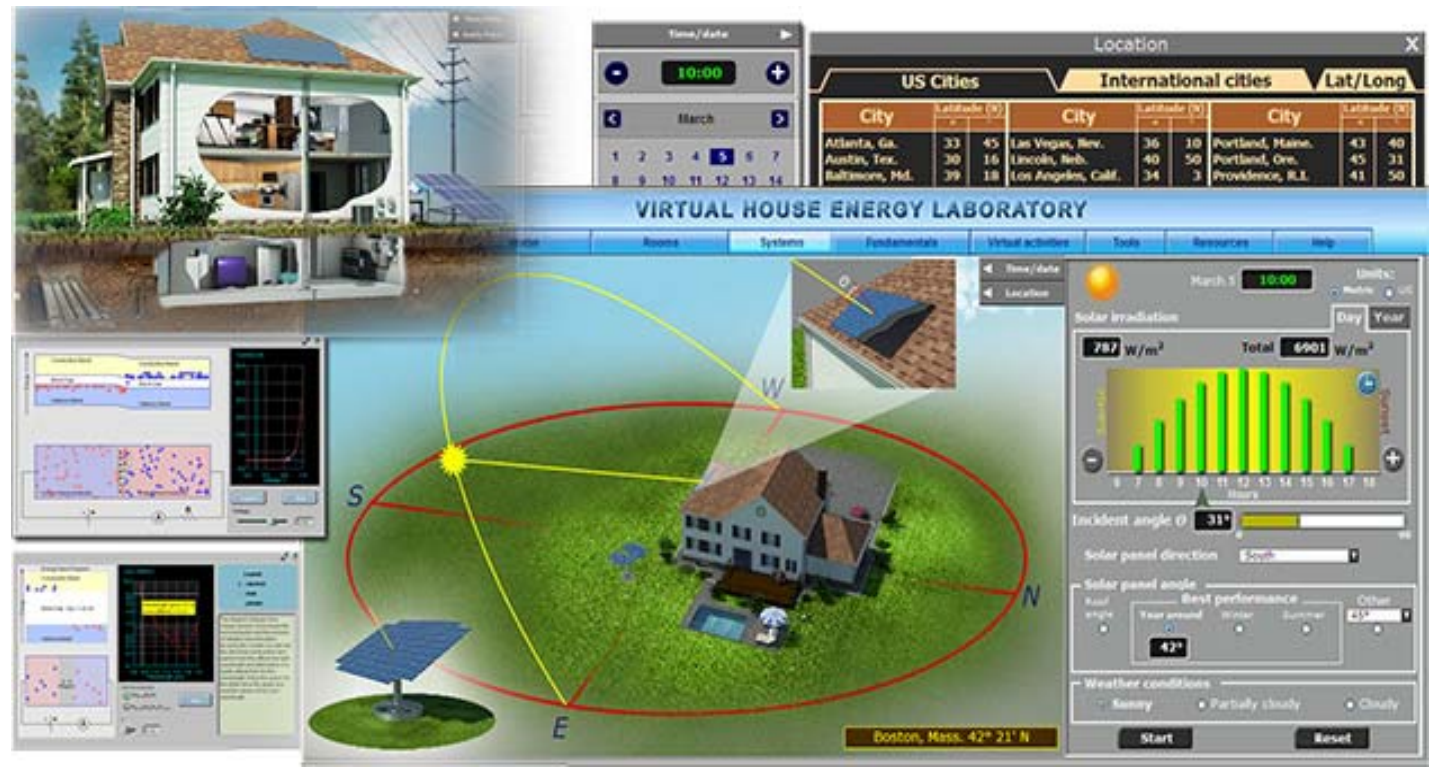

Fig. 3. The set of simulations modeling solar heating and photo-voltaic (PV) systems. Students can change many parameters of the simulations and explore how solar irradiation and efficiency of the systems depends on seasons and daytime (a), geographical location (b), house and panel orientation, weather conditions and some other factors. It is possible to switch between fixed tilt and auto (suntracking) PV systems. Auxiliary simulations (shown in the left) imitate the basic processes in semiconductors responsible for converting, light energy into electricity, which enable students to study photovoltaic effect in semiconductors and explore factors affecting the efficiency of PV panels.

\section{A. Blended (or Hybrid) Laboratories}

A blended (or hybrid) laboratory (Fig. 5) synergizes learning effect of hands-on and online experimentation. In technical training, the combination of hands-on laboratory practice with realistic visualization and interactive online exploration helps connect the development of practical skills with deep understanding of underlying scientific and engineering concepts.

The v-EEH can be connected with real physical sensors. Fig. 4. illustrates how v-EEH parameters such as temperature, humidity and other ambient conditions (such as time of day, sun angle, weather conditions, etc.) may be acquired via real-time data acquisition using low-cost readily available Raspberry Pi and/or Arduino microprocessor/microcontroller platforms and similarly inexpensive sensors. The virtual environment may be synchronized with real-world measured data. Additionally, using a typical smartphone and an app one may control the virtual home appliances and residence HVAC systems and

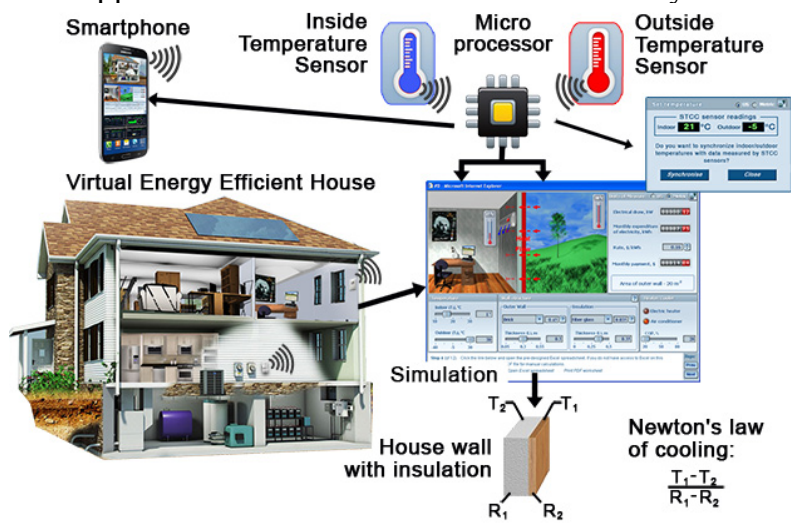

Fig. 4. V-EEH connected with physical sensors. A smartphone through the IoT technology is used to control v-EEH systems and appliances. observe the results of these actions. This type of virtual environment combined with real sensors, wireless communications links, and computing/control platforms provides an example of Internet of Things (IoT) technology. IoT technology is multi-inter-disciplinary in nature and can be utilized in almost any STEM area thus opening up a wealth of possible scenarios using the v-EEH.

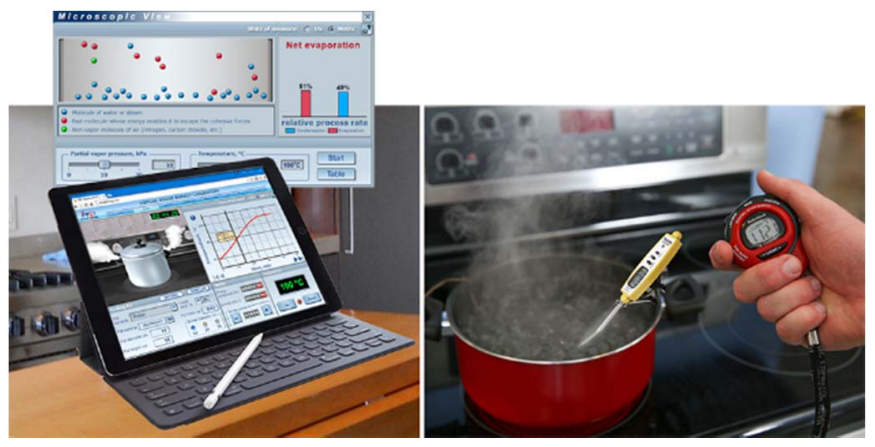

Fig. 5. Blended experiment in which students measure time and energy needed to boil a type of liquid (right) using cooking pots of different sizes, shapes, and made of various materials. In the course of the experiment the ratio of diameters of pots and cooktop burners could be changed as well. The identical experiment is performed online in the v-EEH kitchen (left). Auxiliary simulation (top left) synchronized with the virtual pot dynamically visualizes processes occurring at the microscopic level.

Students observe dynamics of molecular movements and their interactions, collect and analyze measured data. This provides information for evaluating and discussing merits and demerits of different math/science models, as well as factors that impact the process and their contribution to simulated data. Initially designed as an engaging assignment for secondary school students, the experiment turned out to be very useful for undergraduate classes as well. 


\section{B. Gamified Virtual Kitchen}

This Virtual Kitchen helps students study in a highly interactive and gamified manner and gain better understanding of STEM principles and laws relevant to kitchen appliances, cooking, and cookware. Employing a cross-disciplinary approach and a strong connection of the learning context with students' everyday experience helps them to acquire knowledge and skills applicable to solving real life problems.

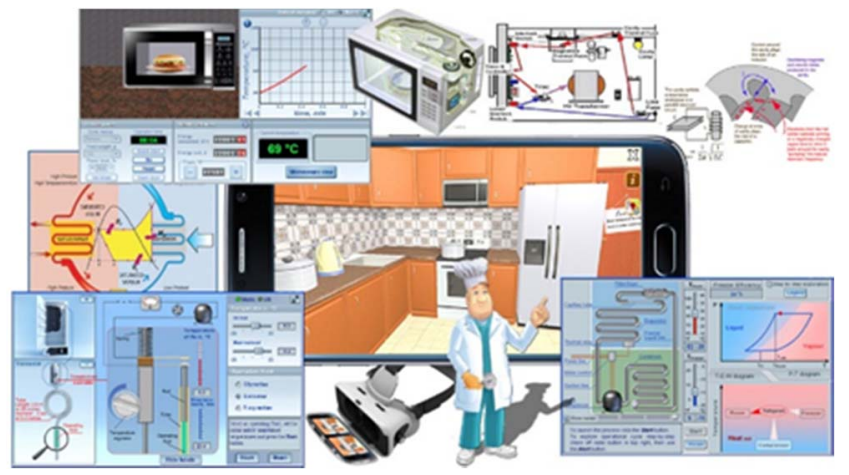

Fig. 6 The gamified 3D version of the virtual kitchen running on a smartphone.

Students can not only navigate through the kitchen, but they also explore the design and operations of home appliances and study underlying fundamental principles, as well as learn about energy efficient cooking technologies. An avatar provides the students with instant feedback, comments and asks questions.

Students have the option to replace conventional appliances with certified energy efficient ones and observe how these replacements affect energy use and the utility bill. Simulations make it possible to visualize the cooking processes and processes responsible for appliances operation and to study related physical, chemical and other phenomena of interest.

Virtual reality (VR) kitchen for smartphones installed on a VR headset provides learners with excitement and virtual reality learning experience.

\section{MULTIFUNCTIONAL VIRTUAL X-RAY LABORATORY}

The virtual X-Ray Laboratory (v-XRLab) has been developed to address such major challenges, as the limited availability of contemporary complex and expensive equipment for educational purposes. Even when accessible, x-ray equipment, due to its full computerized nature and setup, executes most tasks without students' participation. This results in the lack of understanding of equipment operational principles and factors affecting data accuracy. Consequentially, students often cannot correctly estimate reliability of the results and method limitations.equipment for educational purposes. Even when accessible, x-ray equipment, due to its full computerized nature and setup, executes most tasks without students' participation. This results in the lack of understanding of equipment operational principles and factors affecting data accuracy. Consequentially, students often cannot correctly estimate reliability of the results and method limitations.

The described v-XRLab [3] enables undergraduate and graduate students to perform authentic experiments online, using fully functional virtual replicas of actual X-ray diffractometers. It helps learners to: (i) become familiar with nondestructive research and testing methods widely used in science and industry, (ii) explore the design and operation of XRay equipment and its major parts, and (iii) learn underlying scientific and engineering principles and laws. XRLab includes educational analytical and modeling software as well.

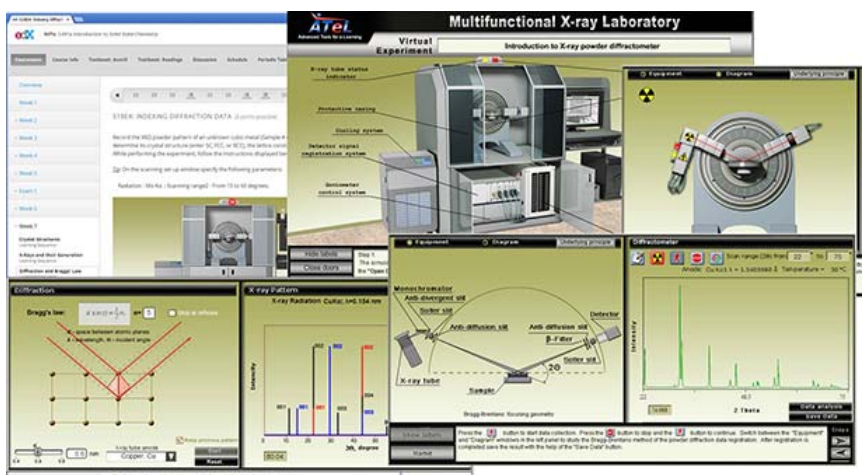

Fig. 7. Virtual X-Ray Diffraction Lab. Students are able to become familiar with design and functionality of an XRD powder diffractometer (top middle), inspect its essential parts inside out and explore underlying science/engineering principles. The student has to select and install a sample, set up scanning parameters and begin scanning. He/she can also peep under a hood and watch either the dynamically displayed goniometer status (middle right) or BraggBrentano diagram (left panel, bottom right). The right panel (bottom right) shows the scattering X-ray pattern being recorded. The instructional panel below the simulation displays step-by-step experiment instructions for the student. The built-in utility allows the student to manually measure peaks positions and intensities and compare patterns. The auxiliary simulation visualizes how XRay beams interact with a crystal lattice and form diffraction peaks (bottom left). Top left screenshot illustrates how $\mathrm{v}$-XRLab is integrated into the massive open online course (MOOC) developed by the Massachusetts Institute of Technology (MIT) Prof. M. Cima and running on edX platform.

Through on-line and blended activities, students gain practical skills required for conducting actual experiments, mastering skills to collect, analyze and interpret experimental data, and examine the factors affecting data accuracy.

The v-XRLab includes simulations, an open library of samples, and expandable sets of online experiments. It also contains supplementary educational resources, authoring tools, and associated cyberinfrastructure. Highly interactive simulations authentically reproduce equipment design and operation and realistically model relevant physical processes.

\section{ENGINES AND POWER PLANTS}

The set of v-Labs "Engines and Power Plants" enables students to learn the design and operations of a turbine, diesel and internal combustion, investigate their operation cycle and study the underlying thermodynamics laws and engineering principles. 


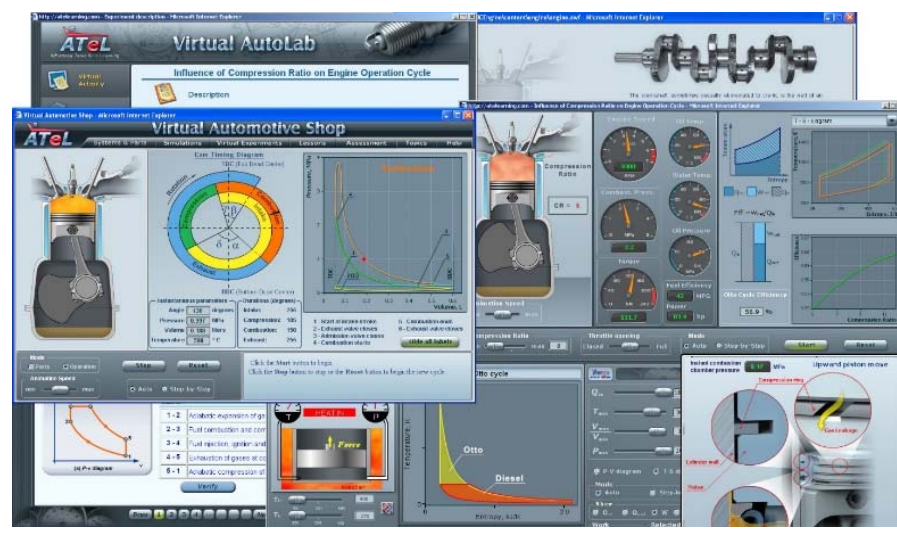

Fig. 8. The simulation, shown in the middle left, dynamically imitates the operation of an internal combustion engine that is linked and synchronized with a Cam Timing Diagram and the chart displaying the Otto cycle (right panel). The student is able to investigate the connections between events taking place in the cylinder and parameter changes at any stage of the cycle. This helps students better appreciate Otto cycle by visualizing how thermodynamic processes occur in an engine. Using the simulation presented in the middle right, students can explore how engine compression and throttle opening affect operating cycle and the influence on engine performance and efficiency. Digital and analog gauges display the major process parameters such as fuel efficiency, torque, power, rotation speed, pressure, oil and water temperatures and oil pressure. The bottom right screenshot shows a fragment of the simulation that was designed to help automotive engineers and technicians, as well as drivers who are eager to know more about vehicle maintenance, explore how piston rings wear impacts engine performance and operation cycle. The simulation shown in the bottom center enable to visually compare different thermodynamics cycles (Otto, Diesel, Rankine, and Carnot) and study their dependency on various parameters. Virtual experiments combine simulations with educational resources and assessments (bottom left).

\section{APPLICATION OF E-LEARNING TOOLS}

Multiple combined and synchronized presentation modes link realistically looking devices/equipment, gauges and processes with abstract engineering diagrams and mathematical plots. This helps learners comprehend interconnection between fundamental science and engineering principles and their practical applications. The virtual labs and e-learning environments have been used at two-year and four-year colleges and universities as follows:

1. As the only tools for practice on the relevant subjects for students enrolled in large-scale lecture classes and in distance learning courses;

2. For preparing students for hands-on practice in actual laboratories;

3. For performance-based assessment of students' ability to operate the equipment and apply gained knowledge for solving practical tasks;

4. For lecture demonstrations;

5. In conjunction with real equipment as an interactive manual and for hybrid experimentation.

Cloud-based and browser accessible v-Labs are not resource-hungry. Offline versions are available as well. The online guidelines help instructors integrate v-Labs into their existing and new curricula.

\section{USER FEEDBACK}

\section{A. Prospects: Students feedback and Assessment}

Some of the requirements for engineering education have changed dramatically following an ongoing integration of information technology and networking of processes and machines in production technology. The ability to visualize data obtained from experiments and to replicate appliances has not only increased access, but also has facilitated access to vast amount of knowledge, whilst at the same time, increasing the skills of learners engaged in science and engineering education. The use of e-learning tools combined with mobiles and fast internet services has continued to contribute to increased pace of development.

Student assessments of the online assignments using current interactive and adjustable cloud-based e-Learning Tools reveal that this e-learning tool provides excellent process visualization accompanied by a good equipment and method overview. This has helped students to develop a deep conceptual understanding. Students also noted that the software is user-friendly and very easy to work with. Students appreciated being able to perform assignments from home at their own pace at a convenient time. This helped them master operational and maintenance skills online and prepared them for more efficient performance of a similar task in the actual x-ray laboratory.

Students also pointed out that the combination of interactive simulations with synchronized online multimedia resources associated with experiments enabled them to perform experimental tasks faster and more meaningfully. Students were interested in the opportunity provided by the cyberinfrastructure, in which cloud-based v-Labs enable the communication with their peers from other schools and even from different countries.

\section{B Provision, Flexibility and Interaction}

According to faculty feedback, v-Labs and relevant simulations allowed them to substantially broaden their instructional palette, create educational content of a greater quality and meaning, and enhance their teaching efficacy. Instructors appreciated the opportunity to adjust exercises and challenge students with practical assignments that otherwise were difficult or even impossible to offer due to the lack of time for hands-on practice and unavailable physical equipment. It also became possible to expand the tasks of experiments.

The modeling tools enabled instructors to prepare samples for X-Ray experiments with tailored characteristics for examination of different residual stresses, textures, and crystallite sizes, offering a larger selection of crystal structures and compositions for investigation.

Faculty who taught specific crystallography courses discovered that deep exploration of design, purpose, and operation of the essential diffractometer components, such as Xray sources, monochromators, slits, filters, detectors, etc. allowed students to better understand the impact of the scanning parameters and geometry on the positions, intensities, and shapes of the reflexes on the XRD patterns. The students were much better at evaluating the reliability and accuracy of 
measured x-ray diffraction data and hence the experimental results. These instructors were also able to offer students assignments that required instant equipment reconfiguration (e.g. "replacing/changing" X-ray tubes, monochromators and detectors) and comparison of data obtained at different experiment conditions.

The authoring toolkit was helpful in personalizing learning assignments and tailoring them to student backgrounds and specific educational goals and course content.

The embedded LCMS (learning/content management system) provided the option of splitting students into small collaborative groups, creating and assigning a separate task for each group or even for each individual student, and keeping track of student performance.

Based on student feedback and faculty observations, virtual experimentation enhanced students' confidence and fostered their self-reliant research capacity. They also helped students to bridge the gap between theoretical knowledge and practical application to analyzing and comparing diffraction data.

\section{WORK IN PROGRESS}

Currently, the virtual v-EEH environment is being modified by faculty of the Open University of Tanzania (OUT) to fit specific African realities including available renewable energy sources and clean cooking techniques.

Online virtual equipment and other interactive e-learning resources are also adjusted to specific requirements of MOOCAfrica and to curricula taught at African schools and universities. The revisions are aimed to help Tanzanian students and students from neighboring and other countries in the African continent to acquire knowledge and skills demanded at local job markets. The goal is to contribute to sustainable socio-economic development through digital delivery strategies, as well as to promote efficient energy technologies and sources for African households, agriculture and food.

\section{CONCLUSION}

The availability and implementation of interactive and adjustable cloud-based e-Learning Tools in engineering education has been greeted with warm embrace and enthusiasm by both students and teachers including employees and employers. However, this has brought some challenges, which need to be considered and addressed robustly through the development and adoption of policies and the deployment of appropriate resources to meet the needs of the various communities of practice. Among outstanding challenges of the field is, for example, a large gap between technology-enabled opportunities in education, conventional pedagogy, and approaches to comprehensively evaluate effects of virtual education on the learning process.

Another issue is related to rapid changes in software/hardware, computer platforms, etc., to which all v-Lab resources and designed environments have to be quickly adapted. With this in mind and to be in line with the growing trend of the majority of students move from PC to mobile, the described virtual laboratories are portable and can run pluginfree on PC, Mac, iPad/iPhone and Android tablets and smartphones under all major web browsers.

After performing virtual experiments and studying the relevant science/engineering subjects using multimedia resources embedded into $\mathrm{v}$-Labs for just-in-time learning, the students felt much more confident and comfortable performing hands-on laboratory assignments. The use of the renewable energy lab by both undergraduate and graduate students at Ulster University (Northern Ireland, UK) has been found quite useful by both students and industrial partners who have observed real research problems successfully tackled through the use of vLabs. The deployment of virtual biomanufacturing laboratories at Quincy College (MA, USA) for training two-year college students and biopharma employees enrolled in professional development programs made them comfortable to perform actual laboratory tasks and enabled faculty to cut conventional hands-on training time by up to $40 \%$. We have also observed that students who performed online tasks prior to in-class sessions were participating in discussions at higher levels of understanding the content than their peers who have not been engaged in the online activities.

We conclude that the availability of these interactive and adjustable cloud-based e-Learning tools in engineering education and practice has opened doors to opportunities which have yet to be envisioned. Some of the challenges centering on development of appropriate pedagogy and determination of correct roll-out strategy are yet to be fully explored. The issue of cost in terms of money and time as well as support for learners most of whom are engaged in flexible and independent learning also need to be looked at and catered for adequately. With rapidly advancing technology in the era of globalization the implementation of virtual educational resources may catalyze a paradigm shift in low cost, high efficiency, quickly adaptable and assessable education and professional development aimed at improving quality of lives of individuals and society. With the right policy, engagement and investment, the use of these tools can contribute to sustainable development and unprecedented economic growth.

\section{REFERENCES}

[1] ATeL Interactive Gamified Multipurpose Web-based educational environment Focused on Sustainable Energy and Energy Efficiency http://atelearning.org/EE/EEHouse presentation/index.php (accessed 11/02/2017)

[2] Y. E. Cherner, M. M. Kuklja, M. J. Cima, et al, The Use of Web-based Virtual X-Ray Diffraction Laboratory for Teaching Materials Science and Engineering, MRS Advances, vol.2, no.31-32, pp.1687-1692, 2017.

[3] ATeL Virtual Laboratories. https://atelearning.com/en-us/demos.php https://atelearning.com/en-us/publications.htm (accessed 11/02/2018).

[4] Contextual Teaching and Learning, Center for Occupational Research and Development (CORD Inc.), Waco, TX, 2008: http://www.cord.org/http://www.cord.org/contextual-teaching-andlearning/ (accessed 11/02/2017).

[5] L. Martin, Learning in Context, ASTC - Resource Center, 2009, http://www.astc.org/resource/education/learning martin.htm (accessed $11 / 02 / 2017)$

[6] A. Y. Kolb, D. A. Kolb, (2011). Kolb Learning Style Inventory 4.0 Boston MA: Hay Group. 